\title{
Tibet The Seed Germination Characteristics Under Low Temperature and Spring Sowing Study of 8 Rapeseed Varieties
}

Jifeng Zhu, Xirong Zhou, Jianxia Jiang, Junying Zhang, Yanli Li, Liyong Yang, Weirong Wang】, Meiyan Jiang®

Shanghai Academy of Agricultural Sciences, Shanghai, 201403 P.R. China

$\not$ Corresponding author email: wangwr71@sina.com; meiyanj423@163.com

Molecular Plant Breeding, 2021, Vol.12, No.16 doi: $10.5376 / \mathrm{mpb} .2021 .12 .0016$

Received: 14 May, 2021

Accepted: 17 May, 2021

Published: 25 May, 2021

Copyright (C) 2021 Zhu et al., This article was first published in Molecular Plant Breeding in Chinese, and here was authorized to translate and publish the paper in English under the terms of Creative Commons Attribution License, which permits unrestricted use, distribution, and reproduction in any medium, provided the original work is properly cited.

Preferred citation for this article:

Zhu J.F., Zhou X.R., Jiang J.X., Zhang J.Y., Li Y.L., Yang L.Y., Wang W.R., and Jiang M.Y., 2021, The seed germination characteristics under low temperature and spring sowing study of 8 rapeseed varieties, Molecular Plant Breeding, 12(16): 1-7 (doi: $\underline{10.5376 / \mathrm{mpb} .2021 .12 .0016)}$

\begin{abstract}
To explore the low temperature germination characteristics of rapeseed, 8 main cultivars were selected for germination experiments in incubators at $20^{\circ} \mathrm{C}, 16^{\circ} \mathrm{C}, 12^{\circ} \mathrm{C}$ and $8^{\circ} \mathrm{C}$, respectively, to measure and analyze the germination potential, germination rate, root length, bud length, etc. The results showed that there was significant difference in the germination potential of tested rapeseeds at temperatures. And the low temperature of $8^{\circ} \mathrm{C}$ was significantly reduced the germination potential. With the decrease of germination temperature, the growth of roots and buds were inhibited significantly. There were significant differences both in temperatures and varieties. The germination potential, root length and bud length could be used as the main index to evaluate seed germination of rapeseed under low temperature. In addition, to screen varieties suitable for spring sowing as green manure, the spring sowing test was carried out. The study found that the fresh grass yield of "Huyouzao No.1" was $1712.53 \mathrm{~kg} / \mathrm{m}^{2}$, which was much higher than other 7 varieties. Its relative root length was second only to "Huyou17" and its relative bud length next to "Huyoufei No. 1 " at $8^{\circ} \mathrm{C}$, respectively. The results can provide a reference for early spring sowing of rapeseed as green manure.
\end{abstract}

Keywords Rapeseed; Seed germination; Low temperature; Spring sowing

Seed germination is the primary stage of crop morphogenesis, which is affected by multiple factors, such as genetics, water, oxygen, temperature. Temperature is an extremely important environmental factor that affects seed germination (Elliott et al., 2011). Suitable temperature promotes germination of seeds, while the seed germination time, seed germination rate and sprouting were declined under low temperature, then affect the uniformity of seedling and growth, and reduce crop yield in the end (Xian et al., 2017). According to most crops, temperature is the most important external factor affecting seed germination under the condition of adequate moisture and sufficient oxygen. Rapeseed (Brassica napus L.) is an important oil crop and green manure crop in China (Cao et al., 2017). $20^{\circ} \mathrm{C} \sim 25^{\circ} \mathrm{C}$ is a suitable temperature for seed germination of rapeseed. With the temperature decreased, the time of seed germination delayed and the germination rate drastically reduced, and the seeds was germinate hardly as temperature dropped to $3^{\circ} \mathrm{C} \sim 4^{\circ} \mathrm{C}$ (Xin et al., 2015; Zhu et al., 2019).

Rapeseed sown late in autumn or in early spring was susceptible to low temperature stress at seed germination stage (Xian et al., 2017). Under low temperature, the rapeseed germination time prolonged and germination rate reduced, affect the uniformity of seedling and growth, sometimes even hurting its growth and production. The rapeseed is mainly distributed in the Yangtze River Basin. With the maturity period extension and the triple-cropping area increase of rice, the late sowing rapeseed is susceptible to low temperature stress, which affect the seedling growth and reduce its wintering rate and yield (Lv et al., 2020). Spring-sown rapeseed as green manure is an effective way to restore and develop green manure production, decrease the usage of chemical fertilizer and pesticides, develop rice green production and protect the ecological environment. The spring sown rapeseed is susceptible to low temperature stress in early spring. Green manure rapeseed in spring mostly planted in March. Meteorological data shows that the highest temperature is mostly below $16^{\circ} \mathrm{C}$, the lowest temperature is mostly above $8^{\circ} \mathrm{C}$ during this period in Yangtze River. Therefore, we selected the local main rapeseed varieties to study the germination under $8{ }^{\circ} \mathrm{C}, 12^{\circ} \mathrm{C}, 16^{\circ} \mathrm{C}$ and $20^{\circ} \mathrm{C}$, and explore the relationship between the low-temperature 
germination characteristics and the fresh grass yield for spring sowing of rapeseed, in order to provide the reference for spring sowing.

\section{Results and Analysis}

\subsection{Responses of different varieties to germination temperatures}

There was no significant difference of the germination potential and the germination rate among the tested varieties. The bud length and root length were significantly different $(p<0.05)$ among breeds, and the fresh weight reach the extremely remarkable level $(p<0.01)$ (Table 1). The results showed that the rapeseed growth rate after germination is related closely with varieties. In tests, the influences temperature on germination potential, bud length, root length and fresh weight of interactions between temperature and variety reached significant level $(p<0.01)$. It showed that temperature was an important factor affecting the germination of rapeseed, and the responses of different varieties to temperature changes were also different. The bud length and root length decreased with temperature decreasing at germination stage and showed greatly affected by temperature. The coefficient of variation (CV) of bud length was $14.44 \%$, the longest was “"Qinza No. 4'xuanxi” (11.08 cm) under $20^{\circ} \mathrm{C}$ and "'Huyou 16 " was shortest $(1.54 \mathrm{~cm})$ under $8^{\circ} \mathrm{C}$. The $\mathrm{CV}$ of root length was $12.01 \%$, the longest was "Huyou039" $(6.74 \mathrm{~cm})$ under $20^{\circ} \mathrm{C}$ and "Huyou21" was shortest $(0.77 \mathrm{~cm})$ under $8^{\circ} \mathrm{C}$. The germination potential was greatly affected by temperature among varieties, which $\mathrm{CV}$ was $8.56 \%$. The germination potential of all varieties reached $86 \%$ under $12^{\circ} \mathrm{C}$ or above it in this study. While the germination potential of all varieties did not attain $28 \%$ under $8^{\circ} \mathrm{C}$. Which indicate that the rapeseed germination potential was sensitive to the low temperature of $8^{\circ} \mathrm{C}$.

To compare the effects of different temperatures on rapeseed germination indicators, the germination indicators were averaged before being analyzed. The germination indicators of rapeseed declined with temperature deceasing, and decreased to be the lowest at $8^{\circ} \mathrm{C}$ (Table 2). Variance analysis showed that the germination potential, germination rate, root length, bud length and fresh weight under $8^{\circ} \mathrm{C}$ were significantly different from that indicators under other temperatures. That means it is more sensitive of rapeseed at germination stage to the low temperature of $8^{\circ} \mathrm{C}$. Compared to $20^{\circ} \mathrm{C}$, there was no significant difference on germination potential and germination rate under both $16^{\circ} \mathrm{C}$ and $12^{\circ} \mathrm{C}$, there was significant difference on root length, bud length and fresh weight under both $16^{\circ} \mathrm{C}$ and $12^{\circ} \mathrm{C}$. There was no significant difference on root length, while significant difference on bud length and fresh weight between $16^{\circ} \mathrm{C}$ and $12^{\circ} \mathrm{C}$.

\subsection{Biomass analysis of spring sown rapeseed}

The growth process of "'Qingza No.4' xuanxi” is the earliest among test rapeseed, which lasted $41 \mathrm{~d}$ from sowing to bolting and 52d from sowing to flowering. "Huyouzao No.1" comes second, which lasted $47 \mathrm{~d}$ from sowing to bolting and 58d from sowing to flowering. Latest was "Huyou17", which lasted 54d from sowing to bolting and $63 \mathrm{~d}$ from sowing to flowering (Table 3). From Table4, "'Qingza No.4' xuanxi” with the highest the plant height $(70.07 \mathrm{~cm})$, "Huyouzao No.1" comes second $(61.47 \mathrm{~cm})$. "Huyou17" and "Huyou039" were short, which plant height was $37.23 \mathrm{~cm}$ and $39.13 \mathrm{~cm}$, respectively. The sowing and initial flowering time of "Huyou21" was next to "Huyouzao No.1", which plant height was $55.17 \mathrm{~cm}$. It showed that the spring-sown rapeseed with a fast growth process has higher plant height.

The fresh weight affects the amount of green manure returning of spring-sown rapeseed. Variety with large biomass has a good application advantages in green manure production. Among the varieties in this study, there were obvious differences of the fresh weights. The CV was $16.19 \%$ and the fresh weight was ranged from 881.80 $\mathrm{g} / \mathrm{m}^{2}$ to $1712.53 \mathrm{~g} / \mathrm{m}^{2}$. The fresh weight was related to the fresh weight of plant and density. There was obvious variation of plant fresh weight in varieties, which $\mathrm{CV}$ was $15.72 \%$ and the variation range was $29.39 \sim 53.52 \mathrm{~g}$. The variation of the density was low, which $\mathrm{CV}$ was $1.85 \%$ and the variation range was $27.00 \sim 32.00 \mathrm{plant} / \mathrm{m}^{2}$. The fresh weight, plant weight and density of "Huyouzao No.1" were the largest in 8 rapeseed varieties. The fresh weight and plant weight of "Huyou21" was second only to "Huyouzao No.1", while its density was low, only 27.36 plant $/ \mathrm{m}^{2}$. There was an obvious difference of plant height among varieties, the CV was $5.99 \%$ and the variation range was $37.23 \sim 70.07 \mathrm{~cm}$ (Table 4). 
Molecular Plant Breeding 2021, Vol.12, No.16, 1-7

$\mathrm{http}: / /$ genbreedpublisher.com/index.php/mpb

Table 1 Comparison of rapeseed germination indicators under different temperatures

\begin{tabular}{|c|c|c|c|c|c|c|}
\hline Material & $\begin{array}{l}\text { Temperature } \\
\left({ }^{\circ} \mathrm{C}\right)\end{array}$ & $\begin{array}{l}\text { Germination } \\
\text { potential (\%) }\end{array}$ & $\begin{array}{l}\text { Germination } \\
(\%)\end{array}$ & rate Bud length $(\mathrm{cm})$ & Root length (cm) & $\begin{array}{l}\text { Weight of } 30 \\
\text { plants }(\mathrm{g})\end{array}$ \\
\hline \multirow[t]{4}{*}{ Huyou16 } & 20 & $94.00 \pm 2.00$ & $96.67 \pm 1.15$ & $8.14 \pm 0.37$ & $6.58 \pm 0.29$ & $2.51 \pm 0.12$ \\
\hline & 16 & $96.00 \pm 4.00$ & $96.67 \pm 3.06$ & $5.29 \pm 0.50$ & $4.49 \pm 0.28$ & $1.92 \pm 0.05$ \\
\hline & 12 & $86.00 \pm 2.00$ & $93.33 \pm 3.06$ & $4.93 \pm 0.18$ & $2.88 \pm 0.27$ & $1.44 \pm 0.11$ \\
\hline & 8 & $27.33 \pm 5.77$ & $92.67 \pm 2.31$ & $1.54 \pm 0.19$ & $1.20 \pm 0.25$ & $1.00 \pm 0.07$ \\
\hline \multirow[t]{4}{*}{ Huyou17 } & 20 & $98.67 \pm 2.31$ & $98.67 \pm 2.31$ & $9.56 \pm 0.53$ & $6.26 \pm 0.30$ & $2.38 \pm 0.07$ \\
\hline & 16 & $100.00 \pm 0.00$ & $100.00 \pm 0.00$ & $5.80 \pm 0.72$ & $4.33 \pm 0.18$ & $1.76 \pm 0.08$ \\
\hline & 12 & $98.00 \pm 0.00$ & $100.00 \pm 0.00$ & $6.71 \pm 0.22$ & $2.82 \pm 0.26$ & $1.30 \pm 0.01$ \\
\hline & 8 & $0.00 \pm 0.00$ & $100.00 \pm 0.00$ & $3.26 \pm 0.37$ & $0.85 \pm 0.05$ & $0.87 \pm 0.01$ \\
\hline \multirow[t]{4}{*}{ Huyou21 } & 20 & $100.00 \pm 0.00$ & $100.00 \pm 0.00$ & $10.08 \pm 0.91$ & $5.19 \pm 0.43$ & $1.94 \pm 0.08$ \\
\hline & 16 & $100.00 \pm 0.00$ & $100.00 \pm 0.00$ & $4.69 \pm 0.18$ & $3.67 \pm 0.21$ & $1.20 \pm 0.05$ \\
\hline & 12 & $97.33 \pm 1.15$ & $98.67 \pm 1.15$ & $6.62 \pm 0.11$ & $2.35 \pm 0.06$ & $0.94 \pm 0.01$ \\
\hline & 8 & $8.67 \pm 2.31$ & $92.67 \pm 4.62$ & $2.75 \pm 0.30$ & $0.77 \pm 0.20$ & $0.63 \pm 0.04$ \\
\hline \multirow[t]{4}{*}{ Huyou25 } & 20 & $100.00 \pm 0.00$ & $100.00 \pm 0.00$ & $9.49 \pm 0.69$ & $6.52 \pm 0.35$ & $1.83 \pm 0.08$ \\
\hline & 16 & $100.00 \pm 0.00$ & $100.00 \pm 0.00$ & $6.51 \pm 0.33$ & $4.76 \pm 0.46$ & $1.34 \pm 0.08$ \\
\hline & 12 & $100.00 \pm 0.00$ & $100.00 \pm 0.00$ & $5.88 \pm 0.85$ & $2.70 \pm 0.37$ & $0.96 \pm 0.06$ \\
\hline & 8 & $0.67 \pm 1.15$ & $96.67 \pm 3.06$ & $1.61 \pm 0.33$ & $0.84 \pm 0.12$ & $0.62 \pm 0.04$ \\
\hline \multirow[t]{4}{*}{ Huyou039 } & 20 & $100.00 \pm 0.00$ & $100.00 \pm 0.00$ & $10.94 \pm 0.20$ & $6.74 \pm 0.13$ & $2.22 \pm 0.08$ \\
\hline & 16 & $100.00 \pm 0.00$ & $100.00 \pm 0.00$ & $5.95 \pm 0.86$ & $4.15 \pm 0.32$ & $1.49 \pm 0.07$ \\
\hline & 12 & $100.00 \pm 0.00$ & $100.00 \pm 0.00$ & $6.89 \pm 0.08$ & $3.12 \pm 0.13$ & $1.24 \pm 0.01$ \\
\hline & 8 & $26.00 \pm 5.29$ & $100.00 \pm 0.00$ & $1.90 \pm 0.10$ & $0.82 \pm 0.07$ & $0.77 \pm 0.02$ \\
\hline \multirow[t]{4}{*}{ Qingza No.4 xuanxi } & 20 & $98.67 \pm 2.31$ & $100.00 \pm 0.00$ & $11.08 \pm 0.52$ & $5.41 \pm 0.63$ & $1.48 \pm 0.09$ \\
\hline & 16 & $99.33 \pm 1.15$ & $99.33 \pm 1.15$ & $6.11 \pm 0.96$ & $3.34 \pm 0.15$ & $0.98 \pm 0.09$ \\
\hline & 12 & $98.00 \pm 2.00$ & $99.33 \pm 1.15$ & $5.90 \pm 0.27$ & $2.19 \pm 0.15$ & $0.83 \pm 0.05$ \\
\hline & 8 & $2.00 \pm 3.46$ & $100.00 \pm 0.00$ & $2.06 \pm 0.15$ & $1.01 \pm 0.09$ & $0.59 \pm 0.02$ \\
\hline \multirow[t]{4}{*}{ Huyouzao No.1 } & 20 & $98.67 \pm 2.31$ & $99.33 \pm 1.15$ & $7.81 \pm 0.34$ & $5.40 \pm 0.37$ & $1.77 \pm 0.01$ \\
\hline & 16 & $99.33 \pm 1.15$ & $99.33 \pm 1.15$ & $4.96 \pm 0.92$ & $3.88 \pm 0.33$ & $1.17 \pm 0.08$ \\
\hline & 12 & $96.00 \pm 2.00$ & $100.00 \pm 0.00$ & $4.45 \pm 0.11$ & $2.69 \pm 0.21$ & $0.96 \pm 0.03$ \\
\hline & 8 & $3.33 \pm 3.06$ & $92.00 \pm 2.00$ & $2.18 \pm 0.26$ & $1.01 \pm 0.14$ & $0.66 \pm 0.02$ \\
\hline \multirow[t]{4}{*}{ Huyoufei No.1 } & 20 & $96.00 \pm 5.29$ & $98.67 \pm 1.15$ & $6.92 \pm 0.60$ & $4.58 \pm 0.43$ & $2.05 \pm 0.05$ \\
\hline & 16 & $95.33 \pm 3.06$ & $98.67 \pm 1.15$ & $6.09 \pm 0.24$ & $3.66 \pm 0.18$ & $1.51 \pm 0.01$ \\
\hline & 12 & $91.33 \pm 4.62$ & $100.00 \pm 0.00$ & $4.41 \pm 0.16$ & $2.98 \pm 0.22$ & $1.20 \pm 0.04$ \\
\hline & 8 & $8.00 \pm 2.00$ & $61.33 \pm 3.06$ & $1.55 \pm 0.22$ & $1.02 \pm 0.18$ & $0.74 \pm 0.03$ \\
\hline \multirow[t]{2}{*}{ Variety } & $F$-Value & 0.67 & 1.20 & 3.05 & 2.83 & 23.12 \\
\hline & $P$-Value & NS & NS & $*$ & $*$ & $* *$ \\
\hline \multirow[t]{2}{*}{ Treatment } & $F$-Value & 371.05 & 2.51 & 100.02 & 207.46 & 226.40 \\
\hline & $P$-Value & $* *$ & NS & $* *$ & $* *$ & $* *$ \\
\hline \multirow[t]{2}{*}{ Variety $\times$ Treatment } & $F$-Value & 111.79 & 1.59 & 32.14 & 64.22 & 84.10 \\
\hline & $P$-Value & $* *$ & NS & $* *$ & $* *$ & $* *$ \\
\hline \multicolumn{2}{|c|}{ Coefficient of variation (\%) } & 8.56 & 6.60 & 14.44 & 12.01 & 7.77 \\
\hline
\end{tabular}

Note: NS means no significant different; *significantly different between treatments at $p<0.05$; **significantly different between treatments at $p<0.01$

Table 2 Effects of temperature on germination indicators of eight rapeseed varieties

\begin{tabular}{llllll}
\hline Temperature $\left({ }^{\circ} \mathrm{C}\right)$ & Germination potential $(\%)$ & Germination rate $(\%)$ & Bud length $(\mathrm{cm})$ & Root length $(\mathrm{cm})$ & Weight of 30 plants $(\mathrm{g})$ \\
\hline 20 & $98.26 \mathrm{a}$ & $99.18 \mathrm{a}$ & $9.25 \mathrm{a}$ & $5.84 \mathrm{a}$ & $2.03 \mathrm{a}$ \\
16 & $98.74 \mathrm{a}$ & $99.25 \mathrm{a}$ & $5.69 \mathrm{~b}$ & $4.05 \mathrm{~b}$ & $1.43 \mathrm{~b}$ \\
12 & $95.83 \mathrm{a}$ & $98.91 \mathrm{a}$ & $5.73 \mathrm{~b}$ & $2.73 \mathrm{c}$ & $1.10 \mathrm{c}$ \\
8 & $9.5 \mathrm{~b}$ & $91.93 \mathrm{~b}$ & $2.13 \mathrm{c}$ & $0.94 \mathrm{~d}$ & $0.74 \mathrm{~d}$ \\
\hline
\end{tabular}

Note: The values in a column followed by different letters are significantly different at $p<0.05$ 
Molecular Plant Breeding 2021, Vol.12, No.16, 1-7

http://genbreedpublisher.com/index.php/mpb

Table 3 Phenological period of rapeseed for spring sowing

\begin{tabular}{llll}
\hline Material & Sowing time & Bolting time & Initial flowering time \\
\hline Huyou16 & $3 / 16$ & $5 / 7$ & $5 / 18$ \\
Huyou17 & $3 / 16$ & $5 / 9$ & $5 / 18$ \\
Huyou21 & $3 / 16$ & $5 / 4$ & $5 / 15$ \\
Huyou25 & $3 / 16$ & $5 / 5$ & $5 / 15$ \\
Huyou039 & $3 / 16$ & $5 / 5$ & $5 / 15$ \\
Qingza No.4 xuanxi & $3 / 16$ & $4 / 26$ & $5 / 7$ \\
Huyouzao No.1 & $3 / 16$ & $5 / 2$ & $5 / 13$ \\
Huyoufei No.1 & $3 / 16$ & $5 / 7$ & $5 / 15$ \\
\hline
\end{tabular}

Note: The values in a column followed by different letters are significantly different at $p<0.05$

Table 4 Some agronomic traits of rapeseed for spring sowing

\begin{tabular}{lllll}
\hline Material & Plant height $(\mathrm{cm})$ & Per plant weight $(\mathrm{g})$ & Density $\left(\mathrm{plants} / \mathrm{m}^{2}\right)$ & Grass yield $\left(\mathrm{g} / \mathrm{m}^{2}\right)$ \\
\hline Huyou16 & $40.44 \pm 1.34 \mathrm{de}$ & $37.74 \pm 10.31 \mathrm{bc}$ & $29.67 \pm 0.58 \mathrm{~b}$ & $1122.83 \pm 322.13 \mathrm{bc}$ \\
Huyou17 & $39.13 \pm 2.34 \mathrm{de}$ & $37.73 \pm 3.78 \mathrm{bc}$ & $27.47 \pm 0.82 \mathrm{c}$ & $1036.81 \pm 108.81 \mathrm{bc}$ \\
Huyou21 & $55.17 \pm 0.85 \mathrm{c}$ & $51.91 \pm 10.89 \mathrm{a}$ & $27.36 \pm 1.10 \mathrm{c}$ & $1419.55 \pm 303.90 \mathrm{ab}$ \\
Huyou25 & $43.57 \pm 4.70 \mathrm{~d}$ & $44.14 \pm 6.82 \mathrm{ab}$ & $30.02 \pm 0.03 \mathrm{~b}$ & $1325.30 \pm 206.27 \mathrm{~b}$ \\
Huyou039 & $37.23 \pm 4.27 \mathrm{e}$ & $29.39 \pm 0.69 \mathrm{c}$ & $30.00 \pm 0.00 \mathrm{~b}$ & $881.80 \pm 20.69 \mathrm{c}$ \\
Qingza No.4 xuanxi & $70.07 \pm 3.72 \mathrm{a}$ & $42.21 \pm 4.36 \mathrm{ab}$ & $30.00 \pm 0.00 \mathrm{~b}$ & $1266.30 \pm 130.76 \mathrm{bc}$ \\
Huyouzao No.1 & $61.47 \pm 2.98 \mathrm{~b}$ & $53.52 \pm 6.09 \mathrm{a}$ & $32.00 \pm 0.00 \mathrm{a}$ & $1712.53 \pm 194.97 \mathrm{a}$ \\
Huyoufei No.1 & $42.67 \pm 1.55 \mathrm{de}$ & $48.58 \pm 4.11 \mathrm{ab}$ & $27.00 \pm 0.00 \mathrm{c}$ & $1311.57 \pm 110.84 \mathrm{~b}$ \\
Coefficient of variation $(\%)$ & 5.99 & 15.72 & 1.85 & 16.19
\end{tabular}

Note: The values in a column followed by different letters are significantly different at $p<0.05$

\subsection{The correlation analysis among rapeseed germination traits and spring sowing biomass}

To analyze the relevance of the rapeseed spring sowing biomass and its germination traits, the relative values of different indicators under $16^{\circ} \mathrm{C}, 12^{\circ} \mathrm{C}$ and $8^{\circ} \mathrm{C}$ for correlation analysis were obtained to compare with $20^{\circ} \mathrm{C}$. The correlation analysis indicated that fresh weight (T1) was marked positive correlated with plant weight (T2) $(r=0.94, p<0.01)$. It showed that there was consistency between the plant weight and the fresh weight for spring sown rapeseed. The fresh weight was positive correlated with the relative bud length, and the density (T18) was positive correlated with the relative germination potential under different temperatures, but that were not significant. So, the rapeseed variety with fast germination has a certain positive effect on its plant growth. There was negative correlation between density and relative root length of $12^{\circ} \mathrm{C}(r=-0.73, p<0.05)$. There were no significantly differences between density and other traits (Table 5).

\section{Discussion}

Increase continuously along with our country food yield and agricultural product security, the agricultural non-point source pollution, farmland degradation to become a count for much problem (Li and Yin., 2019). In response to the problem under the new situation, agricultural green production has been put on the agenda (Li and Yin, 2019). The development of green manure was an important measure to establish the agricultural ecosystem, to promote the green agriculture transition, to improve soil structure and organic matter content, and increase the yield and quality of rice (Cao et al., 2017). There was a lot of winter fallow cropland in south China (Zhao et al., 2012). Rapeseed is the main green manure crop in my country, which distributed widely in the Yangtze River. The use of fallow cropland to develop green manure in spring has a large potential production.

The primary challenge for spring sowing of rapeseed is whether the seeds can germinate normally under low temperature ( $\mathrm{Lv}$ et al., 2019). Low temperature stress in early spring is one of important abiotic factors, low temperature cause seeds hard germinating and seedling, and restrict the population formation and biological yield (Zhang et al., 2020). So, the study rapeseed for response characteristics to different germination temperatures has important applied significance and theoretical. Results of correlation analysis showed that there was relevance between fresh weight and low temperature germination traits, but not reach the significant level. It may be a 
connection with the average temperature after sowing (The daily average temperature within 1 week after sowing was between $13^{\circ} \mathrm{C}$ and $19^{\circ} \mathrm{C}$ ) (Figure 1). The germination potential of all varieties reached $86 \%$ under $12^{\circ} \mathrm{C}$ or above it in this study, and there was no obvious difference among temperatures and varieties. Therefore, the fresh weight depends on plant growth and variety after the spring-sown seedling emergence. When the temperature drops to $8^{\circ} \mathrm{C}$, the germination rate of most varieties reached $80 \%$ need spend 8 days. As cold snap drastically attacks in early spring, the rapeseed creates the serious cold injury to just when the time of germination stage because of the similarly spring cold weather. For example, during the spring sowing experiment in 2020, although the average daily temperature was higher than $10^{\circ} \mathrm{C}$ within 10 days after sowing, the lowest temperature of many days within 2-3 weeks after sowing was lower than $8^{\circ} \mathrm{C}$. Therefore, it is beneficial to the spring-sown green manure development to breed new varieties with high germination potential at $8^{\circ} \mathrm{C}$ to avoid the low-temperature stress after spring sowing.

Table 5 The correlation analysis among rapeseed germination traits and spring sowing biomass.

\begin{tabular}{|c|c|c|c|c|c|c|c|c|c|c|c|c|c|c|c|c|c|}
\hline Trait & $\mathrm{T} 1$ & $\mathrm{~T} 2$ & $\mathrm{~T} 3$ & $\mathrm{~T} 4$ & $\mathrm{~T} 5$ & $\mathrm{~T} 6$ & $\mathrm{~T} 7$ & $\mathrm{~T} 8$ & T9 & $\mathrm{T} 10$ & $\mathrm{~T} 11$ & $\mathrm{~T} 12$ & T13 & $\mathrm{T} 14$ & $\mathrm{~T} 15$ & $\mathrm{~T} 16$ & $\mathrm{~T} 17$ \\
\hline $\mathrm{T} 2$ & $0.94 * *$ & -- & -- & -- & -- & -- & -- & -- & -- & -- & -- & -- & -- & -- & -- & -- & -- \\
\hline $\mathrm{T} 3$ & -0.05 & -0.23 & -- & -- & -- & -- & -- & -- & -- & -- & -- & -- & -- & -- & -- & -- & -- \\
\hline $\mathrm{T} 4$ & -0.12 & -0.17 & -0.35 & -- & -- & -- & -- & -- & -- & -- & -- & -- & -- & -- & -- & -- & -- \\
\hline T5 & -0.52 & -0.56 & 0.22 & -0.51 & -- & -- & -- & -- & -- & -- & -- & -- & -- & -- & -- & -- & -- \\
\hline T6 & -0.24 & -0.15 & 0.00 & 0.00 & -0.05 & -- & -- & -- & -- & -- & -- & -- & -- & -- & -- & -- & -- \\
\hline $\mathrm{T} 7$ & 0.21 & 0.24 & 0.56 & 0.55 & -0.61 & 0.38 & -- & -- & -- & -- & -- & -- & -- & -- & -- & -- & -- \\
\hline $\mathrm{T} 8$ & -0.27 & -0.45 & 0.64 & 0.39 & 0.06 & 0.02 & -0.32 & -- & -- & -- & -- & -- & -- & -- & -- & -- & -- \\
\hline T9 & 0.14 & 0.20 & -0.37 & -0.34 & -0.12 & 0.13 & 0.35 & -0.79 & -- & -- & -- & -- & -- & -- & -- & -- & -- \\
\hline $\mathrm{T} 10$ & -0.39 & -0.16 & -0.29 & 0.03 & 0.04 & $0.87 * *$ & 0.26 & -0.12 & 0.06 & -- & -- & -- & -- & -- & -- & -- & -- \\
\hline $\mathrm{T} 11$ & 0.26 & 0.35 & 0.14 & 0.03 & -0.47 & 0.64 & 0.45 & 0.02 & -0.12 & 0.49 & -- & -- & -- & -- & -- & -- & -- \\
\hline T12 & 0.50 & 0.65 & -0.51 & -0.32 & -0.33 & 0.32 & 0.40 & $-0.80^{*}$ & $0.76^{*}$ & 0.33 & 0.24 & -- & -- & -- & -- & -- & -- \\
\hline $\mathrm{T} 13$ & 0.20 & 0.34 & -0.59 & -0.34 & 0.01 & 0.17 & 0.48 & $-0.94 * *$ & $0.75 *$ & 0.21 & 0.14 & $0.73 *$ & -- & -- & -- & -- & -- \\
\hline $\mathrm{T} 14$ & 0.49 & 0.52 & 0.00 & -0.59 & -0.12 & -0.38 & 0.00 & -0.68 & 0.57 & -0.44 & 0.04 & 0.44 & 0.61 & -- & -- & -- & -- \\
\hline $\mathrm{T} 15$ & -0.30 & -0.33 & 0.15 & -0.40 & 0.14 & 0.12 & -0.05 & -0.24 & 0.69 & 0.29 & -0.09 & 0.34 & 0.22 & 0.13 & -- & -- & -- \\
\hline T16 & -0.37 & -0.41 & 0.07 & -0.32 & 0.29 & -0.08 & 0.07 & -0.39 & 0.61 & -0.20 & -0.26 & 0.01 & 0.47 & 0.50 & 0.59 & -- & -- \\
\hline $\mathrm{T} 17$ & -0.14 & -0.27 & 0.70 & -0.40 & 0.15 & -0.29 & -0.34 & 0.14 & 0.15 & -0.53 & -0.11 & -0.35 & -0.12 & 0.49 & 0.38 & 0.69 & -- \\
\hline $\mathrm{T} 18$ & 0.30 & -0.03 & 0.45 & 0.12 & 0.09 & -0.39 & -0.09 & 0.45 & -0.18 & $-0.73^{*}$ & -0.33 & -0.39 & -0.38 & -0.04 & -0.20 & 0.03 & 0.33 \\
\hline
\end{tabular}

Note: T1: Grass yield $\left(\mathrm{g} / \mathrm{m}^{2}\right)$; T2: Per plant weight $(\mathrm{g})$; T3: Relative germination potential at $16^{\circ} \mathrm{C}$; $\mathrm{T} 4$ : Relative germination potential at $12^{\circ} \mathrm{C}$; T5: Relative germination potential at $8^{\circ} \mathrm{C}$; T6: Relative germination rate at $16^{\circ} \mathrm{C}$; $\mathrm{T} 7$ : Relative germination rate at $12^{\circ} \mathrm{C}$; $\mathrm{T} 8$ : Relative germination rate at $8^{\circ} \mathrm{C}$; T9: Relative root length at $16^{\circ} \mathrm{C}$; T10: Relative root length at $12^{\circ} \mathrm{C}$; $\mathrm{T} 11$ : Relative root length at $8^{\circ} \mathrm{C}$; T12: Relative bud length at $16^{\circ} \mathrm{C}$; T13: Relative bud length at $12^{\circ} \mathrm{C}$; T14: Relative bud length at $8^{\circ} \mathrm{C}$; $\mathrm{T} 15$ : Relative weight at $16^{\circ} \mathrm{C}$; T16: Relative weight at $12^{\circ} \mathrm{C}$; T17: Relative weight at $8^{\circ} \mathrm{C}$; T18: Density (plants $/ \mathrm{m}^{2}$ ); *: significantly different between treatments at $p<0.05 ; * *$ : Significantly different between treatments at $p<0.01$

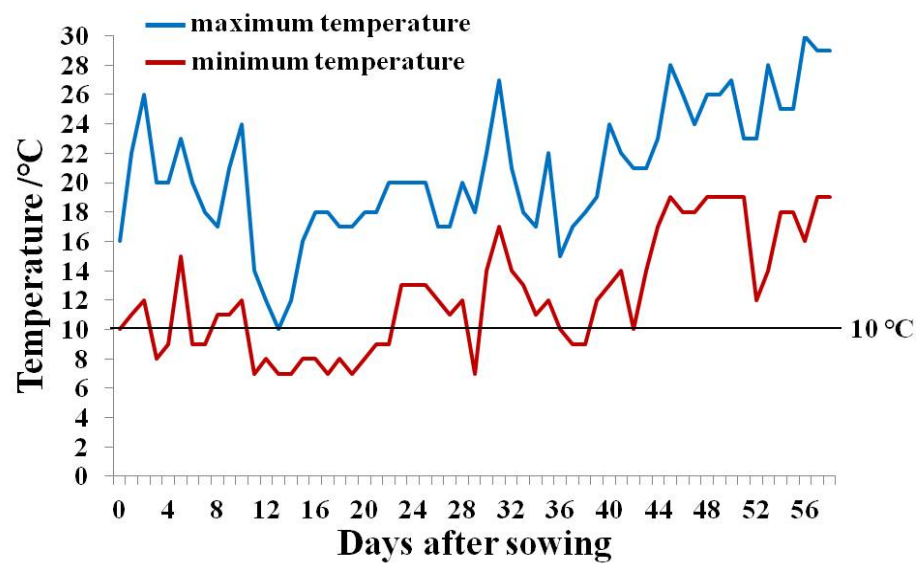

Figure 1 The daily maximum and minimum air temperature ranging after rapeseed spring sowing 
Germination quickly under low temperature is a critical index for plant later growth of rapeseed. Seed germination traits were the comprehensive performance of multiple indicators between gene and environmental interaction (Chinnusamy et al., 2010; Xian et al., 2017). It is important for the evaluation of low-temperature tolerance and identification of variety to establish the low-temperature tolerance evaluating indicator system. The study showed that different germination indicators have different sensitivity to low temperature. Compared to rapeseed germination rate, it was more sensitive to low temperature after germination (Table 2). That means the bud growth of rapeseed was more sensitive to the temperature changing than seed germination. The result was consistent with previous studies of other crops (Chang et al., 2019; Zhang et al., 2020). In addition, 8 varieties were more sensitive to $8^{\circ} \mathrm{C}$ at germination stage, which was consistent with previous study (Zhu et al., 2019). Huang et al. (2019) maintained that the low temperature of $9^{\circ} \mathrm{C}$ has a little effect on germination potential and rate, but greatly affects the index and mean time to germination. There was certain limitation to set the seed germination rate as only assessment index of crop germination trait. This paper selected three indicators of relative root length, relative bud length and relative fresh weight except germination potential and germination rate to evaluate the low-temperature tolerance during germination stage. The results showed the three indicators were sensitive to the temperature changing and had obvious variation among varieties and temperatures. Therefore, the three indicators can be used as the main identification indicators to evaluate tolerance of rapeseed under low temperature during germination stage.

\section{Materials and Methods 3.1 Materials}

"Huyou16", "Huyou17", "Huyou21", "Huyou25", "Huyou039", "Huyoufei No.1", "Huyouzao No.1", and “"Qinza No.4' xuanxi” were selected as materials for low-temperature seed germination experiments and field spring sowing experiments. Among them, "Huyou16", "Huyou17", "Huyou21", "Huyou25" and "Huyou039" are all mid-maturing varieties of rapeseed, which are the main varieties grown in Shanghai. "Huyoufei No.1" and "Huyouzao No.1" are new cultivated green manure varieties. "Qinza No.4' xuanxi" is a self-selected line from early-maturing rapeseed.

\subsection{Methods}

\subsubsection{Seed germination identification}

The seed germination under low-temperature was studied refer to Zhu et al. (2021) in the following steps. 50 fall seeds of each variety were selected from a harvest year to put a culture dish $(9 \mathrm{~cm}$ inner diameter) with sterile filter paper and $20 \mathrm{~mL}$ distilled water. The treatments were put into in man-made climate equipment with different temperatures $\left(20^{\circ} \mathrm{C}, 16^{\circ} \mathrm{C}, 12^{\circ} \mathrm{C}\right.$ and $8^{\circ} \mathrm{C}$, respectively). Each treatment had 3 replicates. The seed germination was investigated from the third day after treatment. And calculate seed germination potential, the seed germination potential $(\%)=$ Germination number on the third day/ the seed number $\times 100 \%$. The test will be finished as seeds germinate not again for 5 consecutive days. Then calculate seed germination rate, the seed germination rate $(\%)=$ the germination number on test end day/ the seed number $\times 100 \%$. In addition, 10 samples of each dish were randomly selected to measure its bud length, root length and 30 plants fresh weight.

\subsubsection{Spring sowing experiment of rapeseed}

The plump seeds of Brassica napus were selected to sow by direct seeding mode on March $16^{\text {th }}, 2020$ in Zhuanghang Experiment Station, Shanghai Academy of Agricultural Sciences. The experimental field was fallow ground with deep plowing after rice reaped. Shallow tillage and stubble cleaning, ditching and ridging, weeding with 10\% glyphosate were measured one week before sowing. Spray herbicide (Acetochlor E.C.) for weed control on the day after sowing. The use complex fertilizer $(25 \mathrm{~kg} / \mathrm{mu})$ as base stage fertilizing and urea $(5 \mathrm{~kg} / \mathrm{mu})$ as top dressing. The plot area was $25 \mathrm{~m}^{2}$ and seeding rate was $25 \mathrm{~g}$. The test was studied by randomizing block arrangement with 3 repeated times. 10 plants from each plot were randomly selected on May $13^{\text {th }}, 2020$. And measuring the plant height, plant weight and plot fresh forage yield. 


\subsubsection{Data processing and analysis}

All traits data were ordered and analyzed by Excel 2010, and calculated the average values, and coefficient of variations. Statistical Analysis of each trait was analyzed by SAS9.2 software.

\section{Authors' contributions}

Zhu Jifeng and Wang Weirong were the executors of this research. Zhu Jifeng completed the data analysis and paper writing. Jiang Meiyan and Zhou Xirong directed the paper modification. Wang Weirong, Jiang Meiyan, Jiang Jianxia, Li Yanli, Zhang Junying, and Yang Liyong participated in the completion of relevant experiments. All authors read and approved the final manuscript.

\section{Acknowledgments}

This study was supported by the National Natural Science Foundation of China (31901502).

\section{References}

Cao W.D., Bao X.G., Xu C.X., Nie J., Gao Y.J., and Geng M.J., 2017, Reviews and prospects on science and technology of green manure in China, Journal of Plant Nutrition and Fertilizer, 23(6): 1450-1461

Chang B.W., Zhong P., Liu J., Tang Z.H., Gao Y.B., Yu H.J., and Guo W., 2019, Effect of low-temperature stress and gibberellin on seed germination and seedling physiological responses in peanut. Acta Agronomica Sinica, 45(1): 122-134 https://doi.org/10.3724/SP.J.1006.2019.84043

Chinnusamy V., Zhu J.K., and Sunkar R., 2010, Gene regulation during cold stress acclimation in plants, Methods in Molecular Biology, 639: 39-55 https://doi.org/10.1007/978-1-60761-702-0_3

Elliott C.W., Fischer D.G., and Leroy C.J., 2011, Germination of three native lupinus species in response to temperature, Northwest Science, 85: 403-410 https://doi.org/10.3955/046.085.0223

Huang H., Yan L., Lv Y., Ding X.Y., Cai J.S., Cheng Y., Zhang X.K., and Zou X.L., 2019, Screening and evaluation of low temperature tolerance of rapeseed (Brassica napus L.) at germination stage, Chinese Journal of Oil Crop Sciences, 41(5): 723-734

Li F.D., and Yin C.B., 2019, Assessment of the functions and ecological services values of green manure in paddy fields in South China, Chinese Joumal of Eco-Agriculture, 27(2): 327-336

Lu Z., Shi D.Y., Gao X.Y., An Y., 2012, Effects of alfalfa green manure on rice yield and soil fertility, Pratacultural Science, 29(7): 1142-1147

Lv Y., Huang Y., Zou X.L., Luo D., Wang X.Y., Bao W.Z., Chen J.J., Ma H.Q., and Cheng Y., 2020, Researches on evaluation, physiological and molecular mechanism of rapeseed low-temperature resistance, Chinese Journal of Oil Crop Sciences, 42(4): 527-535

Xian M., Luo T., Khan M.N., Hu L.Y., and Xu Z.H., 2017, Identifying differentially expressed genes associated with tolerance against low temperature stress in Brassica napus through transcriptome analysis, International Journal of Agriculture and Biology, 19: 273-281 https://doi.org/10.17957/IJAB/15.0274

Xian M.Z., Yang P., Hu L.Y., Xu Z.H., 2015, Comprehensive evaluation of low temperature tolerance in rapeseed during germination and emergence periods, Crops, 0(5): 116-122

Zang R.D., Xiao M.Y., Xu X.X., Jiang B., Xing Y.F., Chen X.F., Li B., Ai X.Y., Zhou Y.F., and Huang R.D., 2020, Responses of sorghum hybrids to germination temperatures and identification of low temperature resistance, Zuowu Xuebao (Acta Agronomica Sinica), 46(6): 889-901 https://doi.org/10.3724/SP.J.1006.2020.94150

Zhu J.F., Zhang J.Y., Qin Q.W., Wang W.R., Chu H.W., Zhou X.R., and Li Y.L., 2021, Collection and evaluation of sugar sorghum germplasm resources in Shanghai, Molecular Plant Breeding, https://kns.cnki.net/kcms/detail/46.1068.S.20210107.1117.002.html

Zhu J.F., Zhang J.Y., Yang L.Y., Jiang M.Y., Jiang J.X., Li Y.L., Wang W.R., and Zhou X.R., 2019, Identification of rape (Brassica napus L.) germplasm resources with low temperature germination tolerance, Acta Agriculturae Shanghai, 35(4): 22-27 